\title{
Efficacy of colonoscopy after an episode of acute diverticulitis and risk of colorectal cancer
}

\author{
Jeancarlos Jhosmer Trujillo Díaz, ${ }^{\mathrm{a}, \mathrm{b}}$, Beatriz De Andrés Asenjo ${ }^{\mathrm{a}, \mathrm{b}}$, María Ruiz Soriano ${ }^{\mathrm{a}}$, \\ Carlos Jezieniecki Fernándeza , Javier Ortiz de Solórzano Aurusa ${ }^{a}, \mathrm{~b}$, Juan Pablo Beltrán de Heredia y Rentería \\ Valladolid University Clinic Hospital, Spain
}

\begin{abstract}
Background Diverticular disease of the colon has a high global prevalence. The guidelines suggest performing a colonoscopy 4-6 weeks after the acute episode to exclude colorectal cancer (CRC). However, these recommendations are based on old studies, when computed tomography was not used to diagnose acute diverticulitis $(\mathrm{AD})$. There are currently some studies showing that CRC incidence is low in uncomplicated $\mathrm{AD}$ (UAD). Therefore, we decided to perform this study to determine the CRC incidence after an $\mathrm{AD}$ episode and the diagnostic efficacy of colonoscopy in these patients.
\end{abstract}

Method This was a retrospective cohort study that included patients with AD between July 2016 and December 2017.

Results One hundred seventy-four patients had AD. Of these, 46 patients were excluded and we analyzed 128 patients, $72(56.3 \%)$ women and $56(43.7 \%)$ men. Ninety $(70.3 \%)$ had UAD and $38(29.7 \%)$ complicated AD (CAD). The colonoscopy showed lesions in 18 (14.06\%), 5 (3.9\%) being CRC. The patients with $\mathrm{CRC}$ had shown $\mathrm{CAD}$ and were $>70$ years old $(\mathrm{P}=0.0001$ and $\mathrm{P}=0.002$ respectively).

Conclusions Routine colonoscopy in patients with UAD appears not have many benefits as a diagnostic tool. However, it has a higher efficacy if the patients have CAD and are $>70$ years old.

Keywords Colonic diverticular disease, acute diverticulitis, colorectal cancer, colonic neoplasm, colonoscopy

Ann Gastroenterol 2020; 33 (1): 1-5

\section{Introduction}

Colonic diverticular disease is a pathology with a high prevalence throughout the world, being most prevalent in developed countries, and whose incidence is increasing. It is estimated that $5-10 \%$ of the population $>45$ years old and approximately $80 \%$ of those $>85$ years old suffer this pathology [1-4]. The economic impact due to episodes of acute diverticulitis (AD) has been estimated at approximately $\$ 3,500-12,800$ for each patient admitted, depending on the length of stay and the type of treatment performed [5].

${ }^{\text {a} D e p a r t m e n t ~ o f ~ G e n e r a l ~ a n d ~ D i g e s t i v e ~ S u r g e r y, ~(J e a n c a r l o s ~ J h o s m e r ~}$ Trujillo Díaz, Beatriz De Andrés Asenjo, María Ruiz Soriano, Carlos Jezieniecki Fernández, Javier Ortiz de Solórzano Aurusa, Juan Pablo

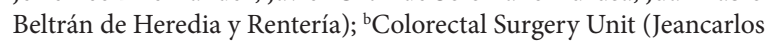
Jhosmer Trujillo Díaz, Beatriz De Andrés Asenjo, Javier Ortiz de Solórzano Aurusa), Valladolid University Clinic Hospital, Spain

Conflict of Interest: None

Correspondence to: Jeancarlos Jhosmer Trujillo Díaz, Department of General and Digestive Surgery, Valladolid University Clinic Hospital, Av. Ramón y Cajal 3, 47003, Valladolid, Spain, e-mail: jeancar5671@gmail.com

Received 15 June 2019; accepted 14 October 2019; published online 29 November 2019

DOI: https://doi.org/10.20524/aog.2019.0437
Its pathogenesis is still not fully known, but could be related to changes in the structure and resistance of the colonic wall, due to alterations in intestinal motility or diets lacking in fiber, which cause herniation of the mucosa and submucosa leading to diverticula formation [1]. Most patients with this pathology are asymptomatic, but approximately $25 \%$ of them may suffer an episode of $\mathrm{AD}$, which can be complicated by the formation of abscesses, fistulas or colonic perforation $[2,4]$.

Historically and currently, the guidelines recommend performing a routine colonoscopy 4-6 weeks after the acute episode of AD to confirm the diagnosis and to exclude the presence of advanced adenomas (AA) and colorectal cancer (CRC). However, these recommendations are based on old studies, when computed tomography (CT) was not used to diagnose $\mathrm{AD}[6]$. In the last few years, some studies have attempted to demonstrate that it is not necessary to perform a routine colonoscopy in all patients with $\mathrm{AD}$, because the incidence of $\mathrm{AA}$ and $\mathrm{CRC}$ in uncomplicated $\mathrm{AD}$ patients (UAD) is low and almost similar to that found in CRC population screening, whereas it would be necessary in patients with complicated $\mathrm{AD}(\mathrm{CAD})[6,7]$.

Given the controversy between the guidelines and the latest published studies, we decided to perform this study to assess the real incidence of CRC after an episode of $\mathrm{AD}$, both complicated and uncomplicated, found by colonoscopy, and to determine whether a colonoscopy should really be necessary for all patients with $\mathrm{AD}$. 


\section{Patients and methods}

We conducted a retrospective cohort study that included adult patients treated in the Surgery Department at the Valladolid University Clinic Hospital, Spain, between July 2016 and December 2017, with a diagnosis based on clinical (abdominal pain, fever) and analytical (leukocytosis, elevation of C-reactive protein [CRP]) data, and confirmed by $\mathrm{CT}$ during a first episode of $\mathrm{AD}$. We excluded patients with a history of CRC, as well as those who underwent colonoscopy before the episode of $\mathrm{AD}$ and patients who had no follow-up colonoscopy. UAD was defined as a thickening of the colonic wall and/or increased density of pericolonic fat, $\leq \mathrm{Ia}$ according to the modified Hinchey classification (mHinchey), whereas CAD was associated with the presence of abscesses, fistula, intestinal occlusion and/or pneumoperitoneum, mHinchey $\geq \mathrm{Ib}$.

The Hinchey classification has traditionally been used to distinguish 4 stages of perforated diverticular colonic disease; Hinchey et al published it in 1978 [8]. Since the introduction of CT, the Hinchey classification has been modified based on radiological findings. The modification by Kayser et al [9] was used in this study. The Hinchey classification as modified by Kayser et al includes 6 stages based on radiological findings: stage 0 , diverticulitis \pm colonic wall thickening; stage Ia: colonic wall thickening with pericolic soft tissue changes; stage Ib, Ia changes + pericolic or mesocolic abscess; stage II, Ia changes + distant abscess (generally deep in the pelvis or interloop regions); stage III, free perforation with purulent peritonitis; and stage IV, the same findings as stage III plus fecal peritonitis [10,11].

The colonoscopy was performed during follow up between 6 and 12 months. The diagnosis of CRC was based on the pathological result of the colonoscopy biopsy or the surgical specimen. The study was approved by the local institutional review board, clinical research ethics committee, Valladolid University Clinic Hospital, Spain.

\section{Statistical analysis}

Data analysis was carried out using the statistical program SPSS version 24 (IBM, Chicago, IL, USA). Chi-square and Student's $t$-test were performed for the categorical and numerical variables respectively. Statistical significance was defined as $\mathrm{P}<0.05$.

\section{Results}

A total of 174 patients were diagnosed clinically and radiologically with AD. Forty-six patients were excluded because colonoscopy was not performed during follow up. Finally, we analyzed a total of 128 patients. The median age of the patients in our study was 67.5 years, and $72(56.3 \%)$ patients were women. A total of $90(70.3 \%)$ patients had UAD and 38 (29.7\%) CAD. The location of the $\mathrm{AD}$ was $89.08 \%$ in the sigmoid colon, $9.36 \%$ in the descending colon and $1.56 \%$ in the ascending colon. Twenty-seven $(21.1 \%)$ patients required surgery, performed through a laparoscopic approach in $10(37 \%)$ patients (Table 1$)$.

The colonoscopy performed after the episode of AD showed lesions in 18 (14.06\%) patients. Eight (6.25\%) patients in the CAD group had $3(2.34 \%)$ non-advanced adenomas (NAA) and 5 (3.9\%) CRC. Ten (7.81\%) patients with UAD had NAA and none had CRC (Fig. 1). No adverse events secondary to colonoscopy were evidenced.

The incidence of CRC, length of stay and CRP values were higher in patients with $\mathrm{CAD}(\mathrm{P}=0.0001, \mathrm{P}=0.002$ and $\mathrm{P}=0.008$ respectively) (Table 2). Patients with $\mathrm{CRC}$ were older and had lower hemoglobin values ( $\mathrm{P}=0.002$ and $\mathrm{P}=0.009$ respectively). In addition, patients older than 70 had a higher incidence of CRC ( $\mathrm{P}=0.009)$ (Table 3$)$.

\section{Discussion}

Colorectal cancer and colonic diverticular disease share multiple epidemiological characteristics. Both are very frequent pathologies in the Western world, with an incidence that increases with age, and a higher prevalence in men. In the west, the most frequent location of diverticular disease and CRC is the left colon $[3,12]$.

Currently, most international clinical guidelines, as well as the American Gastroenterological Association [13] and the Society of American Gastrointestinal and Endoscopic Surgeons [14], recommend performing a routine colonoscopy or CT colonography after an episode of $\mathrm{AD}$ to exclude the presence of CRC. However, nowadays these recommendations are controversial, because they were based on old studies in which the diagnosis of $\mathrm{AD}$ was determined by clinical, analytical and imaging tests-such as barium enema, abdominal ultrasound, and CT - that were of inferior quality and resolution compared to current modalities [5,15-17]. In addition, invasive procedures are not exempt from complications and they entail a risk of morbidity and mortality. Colonoscopy is associated with a risk of colonic perforation in between $0.1-0.2 \%$ of patients and also a risk of producing iatrogenic diverticulitis $[6,16]$.

Nowadays, CT has revolutionized the diagnosis and management of colonic diverticular disease. Multidetector CT can obtain thinner sections and has a better resolution and images of higher quality $[6,17]$. It is presently considered the best imaging technique for the diagnosis of $\mathrm{AD}$ and its complications, with a sensitivity and specificity of $94 \%$ and $99 \%$ respectively $[4,18,19]$.

There are some studies that do not recommend routine colonoscopy in all patients with $\mathrm{AD}$. Sharma et al performed a meta-analysis in which they included 11 studies, with a total of 1970 patients diagnosed with AD by CT; they found a higher CRC incidence in patients with CAD compared to those with UAD ( $10.8 \%$ vs. $0.7 \%, P \leq 0.001)$, with an overall CRC incidence of $1.6 \%$ [6]. Another systematic review performed by De Vries et al, in which 2490 patients with UAD were included, found that $11 \%$ of the patients had CRC and $2.2 \%$ AA; they concluded that performing a routine colonoscopy after an episode of UAD is not necessary unless there are signs of CRC [7]. There are also other more recent retrospective studies, such as those performed 
Table 1 Demographic, clinical and analytical characteristics of acute diverticulitis patients

\begin{tabular}{|c|c|c|}
\hline Characteristics & n (\%) & Range \\
\hline \multicolumn{3}{|l|}{ Sex } \\
\hline Female & $72(56.3 \%)$ & \\
\hline Male & $56(43.7 \%)$ & \\
\hline Age (median) & 67.5 years & IQR: $56.3-77.5$ years \\
\hline Length of stay (median) & 6 days & IQR: 5-8 days \\
\hline $\begin{array}{l}\text { Comorbidities } \\
\text { Arterial hypertension } \\
\text { Diabetes mellitus } \\
\text { Dyslipidemia } \\
\text { COPD }\end{array}$ & $\begin{array}{c}63(49.2 \%) \\
13(10.3 \%) \\
50(39.7 \%) \\
11(8.7 \%)\end{array}$ & \\
\hline $\begin{array}{l}\text { Analytics } \\
\text { Hemoglobin (mean) } \\
\text { Leukocytes (median) } \\
\text { CRP (median) }\end{array}$ & $\begin{array}{c}13.88 \pm 1.7 \mathrm{~g} / \mathrm{dL} \\
12.73 \times 10^{3} / \mu \mathrm{L} \\
68.2 \mathrm{mg} / \mathrm{L}\end{array}$ & $\begin{array}{l}\text { Range: } 8.6-18.5 \mathrm{~g} / \mathrm{dL} \\
\text { IQR: } 10.68-14.89 \times 10^{3} / \mu \mathrm{L} \\
\text { IQR: } 31.85-139.5 \mathrm{mg} / \mathrm{dL}\end{array}$ \\
\hline $\begin{array}{l}\text { Modified Hinchey classification } \\
\text { Ia } \\
\text { Ib } \\
\text { II } \\
\text { III } \\
\text { IV }\end{array}$ & $\begin{array}{c}90(70.3 \%) \\
22(17.2 \%) \\
9(7 \%) \\
4(3.1 \%) \\
3(2.3 \%)\end{array}$ & \\
\hline $\begin{array}{l}\text { Diverticulitis location } \\
\text { Sigmoid colon } \\
\text { Descending colon } \\
\text { Ascending colon }\end{array}$ & $\begin{array}{c}114(89.08 \%) \\
12(9.36 \%) \\
2(1.56 \%)\end{array}$ & \\
\hline $\begin{array}{l}\text { Surgery } \\
\text { Sigmoidectomy } \\
\text { Left colectomy } \\
\text { Laparoscopic lavage and drainage }\end{array}$ & $\begin{array}{c}27(21.1 \%) \\
21 \\
2 \\
4\end{array}$ & \\
\hline
\end{tabular}

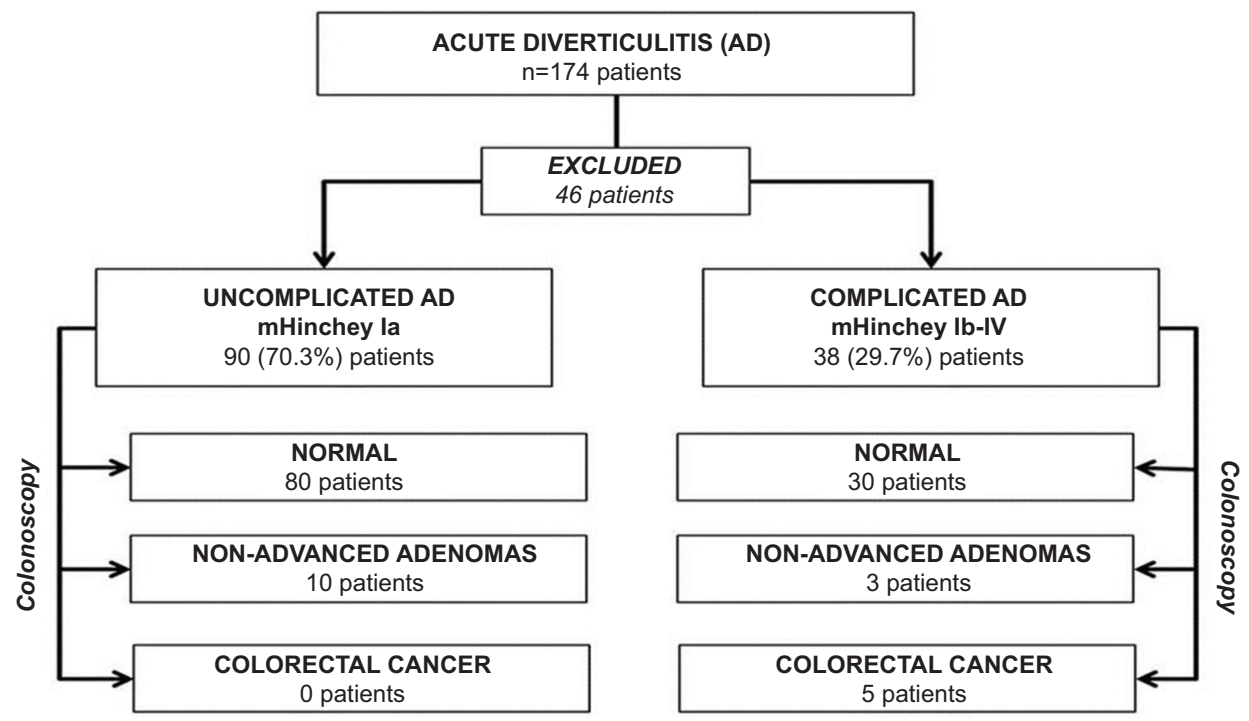

Figure 1 Flow chart of patients through the study

by Daniels, Horesh, Suhardja and Khoury, which also concluded that the incidence of CRC is not higher in patients with $\mathrm{AD}$, so a routine colonoscopy should not be necessary [16,20-22].
A retrospective study carried out by Ramphal et al found that the CRC risk in patients with UAD without warning symptoms was lower than in those who present such symptoms $(0.2 \%$ vs. 


\section{J. J. T. Díaz et al}

Table 2 Comparative outcomes of the main characteristics between complicated and uncomplicated acute diverticulitis

\begin{tabular}{|c|c|c|c|}
\hline Characteristics & $\mathrm{CAD}$ & UAD & $\mathrm{P}$-value \\
\hline $\begin{array}{l}\text { Sex } \\
\quad \text { Female } \\
\text { Male }\end{array}$ & $\begin{array}{l}18(14.1 \%) \\
20(15.6 \%)\end{array}$ & $\begin{array}{l}54(42.2 \%) \\
36(28.1 \%)\end{array}$ & 0.18 \\
\hline Age & $65.61 \pm 15.8$ years & $66.66 \pm 12.6$ years & 0.69 \\
\hline Length of stay & $12.71 \pm 11.9$ days & $6.08 \pm 2.2$ days & 0.002 \\
\hline $\begin{array}{l}\text { Comorbidities } \\
\text { Diabetes mellitus } \\
\text { Arterial hypertension } \\
\text { Dyslipidemia } \\
\text { COPD }\end{array}$ & $\begin{array}{c}1(2.6 \%) \\
15(11.7 \%) \\
12(9.4 \%) \\
2(1.6 \%)\end{array}$ & $\begin{array}{c}12(9.4 \%) \\
48(37.5 \%) \\
39(30.5 \%) \\
9(7 \%)\end{array}$ & $\begin{array}{l}0.06 \\
0.15 \\
0.21 \\
0.38\end{array}$ \\
\hline Colorectal cancer & 5 & 0 & 0.0001 \\
\hline $\begin{array}{l}\text { Analytics } \\
\text { Hemoglobin } \\
\text { Leukocytes } \\
\text { CRP }\end{array}$ & $\begin{array}{c}13.82 \pm 2.1 \mathrm{~g} / \mathrm{dL} \\
14.09 \pm 6.5 \times 10^{3} / \mu \mathrm{L} \\
117.23 \pm 80.4 \mathrm{mg} / \mathrm{L}\end{array}$ & $\begin{array}{c}13.91 \pm 1.6 \mathrm{~g} / \mathrm{dL} \\
13.15 \pm 6.0 \times 10^{3} / \mu \mathrm{L} \\
76.67 \pm 67.79 \mathrm{mg} / \mathrm{L}\end{array}$ & $\begin{array}{c}0.8 \\
0.45 \\
0.008\end{array}$ \\
\hline $\begin{array}{l}\text { Surgery } \\
\text { Sigmoidectomy } \\
\text { Left colectomy } \\
\text { Laparoscopic lavage and drainage }\end{array}$ & $\begin{array}{c}24(18.8 \%) \\
18 \\
2 \\
4\end{array}$ & $\begin{array}{c}3(2.3 \%) \\
3 \\
0 \\
0\end{array}$ & 0.0001 \\
\hline
\end{tabular}

$\overline{C A D}$, complicated acute diverticulitis; UAD, uncomplicated acute diverticulitis; COPD, chronic obstructive pulmonary disease; CRP, C-reactive protein

Table 3 Comparative outcomes of the main characteristics between group with and without colorectal cancer

\begin{tabular}{|c|c|c|c|}
\hline Characteristics & CRC & Without CRC & P-value \\
\hline \multicolumn{4}{|l|}{ Sex } \\
\hline Female & $3(2.3 \%)$ & $69(53.9 \%)$ & 0.8 \\
\hline Male & $2(1.6 \%)$ & $54(42.2 \%)$ & \\
\hline Age & $81.4 \pm 6.2$ years & $65.73 \pm 13.5$ years & 0.002 \\
\hline Length of stay & $18.8 \pm 9.9$ days & $7.61 \pm 6.9$ days & 0.064 \\
\hline \multicolumn{4}{|l|}{ Comorbidities } \\
\hline Diabetes mellitus & 0 & $13(10.2 \%)$ & 0.4 \\
\hline Arterial hypertension & $3(2.3 \%)$ & $60(46.9 \%)$ & 0.6 \\
\hline Dyslipidemia & $3(2.3 \%)$ & $48(37.5 \%)$ & 0.34 \\
\hline COPD & $1(0.8 \%)$ & $10(7.8 \%)$ & 0.35 \\
\hline Alcohol consumption & 0 & $3(2.3 \%)$ & 0.7 \\
\hline Smoking & $1(0.8 \%)$ & $18(14.1 \%)$ & 0.7 \\
\hline Modified Hinchey classification & & & 0.002 \\
\hline Ia & 0 & $90(70.3 \%)$ & \\
\hline $\mathrm{Ib}$ & $3(2.3 \%)$ & $19(14.8 \%)$ & \\
\hline II & $2(1.6 \%)$ & $7(5.5 \%)$ & \\
\hline III & 0 & $4(3.1 \%)$ & \\
\hline IV & 0 & $3(2.3 \%)$ & \\
\hline \multicolumn{4}{|l|}{ Analytics } \\
\hline Hemoglobin & $11.08 \pm 1.4 \mathrm{~g} / \mathrm{dL}$ & $14 \pm 1.7 \mathrm{~g} / \mathrm{dL}$ & 0.009 \\
\hline Leukocytes & $12.17 \pm 3.9 \times 10^{3} / \mu \mathrm{L}$ & $13.48 \pm 6.6 \times 10^{3} / \mu \mathrm{L}$ & 0.5 \\
\hline $\mathrm{CRP}$ & $162.64 \pm 86.7 \mathrm{mg} / \mathrm{L}$ & $85.7 \pm 72.1 \mathrm{mg} / \mathrm{L}$ & 0.11 \\
\hline
\end{tabular}

CRC, colorectal cancer; COPD, chronic obstructive pulmonary disease; CRP, C-reactive protein

4.4\%, $\mathrm{P}=0.0002)$, so they recommend that colonoscopy be performed only in patients with warning symptoms of $\mathrm{CRC}$, such as lower gastrointestinal bleeding, constitutional syndrome and/or persistent abdominal pain [12].

However, there are also some studies that continue to recommend performing a routine colonoscopy. Meireles et al performed a retrospective study with 427 patients, and through colonoscopies they found lesions compatible with CRC in $20(4.7 \%)$ patients. This finding was greater in complicated $\mathrm{AD}(10 \%$ vs. $3.5 \%, \mathrm{P}=0.021)$, so they recommend that colonoscopies should continue to be performed after an episode of $\mathrm{AD}$, especially in patients older than 50 years [1]. Soh et al also carried out a retrospective study in Asia that included 135 patients with UAD. Through colonoscopies they 
found 2 (1.5\%) patients with AA and 2 (1.5\%) with CRC. They advised that a follow-up colonoscopy should be performed in UAD patients [19].

In our study we found that the overall incidence of CRC was $3.9 \%$ and that of NAA was $10.15 \%$, being slightly higher than in the previously mentioned studies, but not higher than in the colonoscopies of CRC population screening. Another significant finding was that all patients with CRC presented CAD and were older than 70 years $(\mathrm{P}=0.009)$.

The findings of this study have to be seen in light of some limitations. First, it was performed in a single center, it was a retrospective study and only a small number of patients were included. Despite these limitations and based on our findings, in agreement with the few existing studies, we can say that a routine colonoscopy should not be performed in all patients with $\mathrm{AD}$. However, patients with CAD (mHinchey $\geq \mathrm{Ib}$ ) and those older than 70 could benefit from undergoing a colonoscopy after an episode of $\mathrm{AD}$, because the $\mathrm{CRC}$ incidence is higher in these cases.

To conclude, in our environment, routine colonoscopy in patients with UAD (mHinchey $\leq \mathrm{Ia}$ ) has few benefits because the incidence of CRC is similar to that found through CRC population screening. However, the efficacy of colonoscopy is higher if it is performed in patients with CAD (mHinchey $\geq \mathrm{Ib}$ ) and in those older than 70 , so in these patients it would be advisable to perform it routinely.

\section{Summary Box}

\section{What is already known:}

- Colonic diverticular disease and colorectal cancer (CRC) share epidemiological characteristics

- The guidelines recommend performing a colonoscopy after an episode of acute diverticulitis (AD)

\section{What the new findings are:}

- Routine colonoscopy should not be performed in all patients with $\mathrm{AD}$

- Colonoscopy should be performed in patients with complicated $\mathrm{AD}$ and those older than 70 years because they have a higher risk of CRC

\section{References}

1. Meireles LC, Fernandes SR, Ribeiro LC, Velosa J. Role of endoscopy after an acute episode of diverticulitis: analysis of a cohort of Portuguese patients from a tertiary referral center. Eur J Gastroenterol Hepatol 2015;27:1429-1432.

2. Ramphal W, Schreinemakers JM, Seerden TC, Crolla RM, Rijken AM, Gobardhan PD. What is the risk of colorectal cancer after an episode of acute diverticulitis in conservatively treated patients?. J Clin Gastroenterol 2016;50:e35-e39.

3. Khoury T, Mahamid M, Lubany A, et al. Underlying colorectal cancer was rarely detected after an episode of acute diverticulitis: a retrospective analysis of 225 patients. J Gastrointest Cancer 2019 Jan 10 [Epub ahead of print]. doi: 10.1007/s12029-01900202-3.

4. Seoane Urgorri A, Zaffalon D, Pera Román M, et al. Routine lower gastrointestinal endoscopy for radiographically confirmed acute diverticulitis. In whom and when is it indicated? Rev Esp Enferm Dig 2018;110:571-576.

5. Walker AS, Bingham JR, Janssen KM, et al. Colonoscopy after Hinchey I and II left-sided diverticulitis: utility or futility? Am J Surg 2016;212:837-843.

6. Sharma PV, Eglinton T, Hider P, Frizelle F. Systematic review and meta-analysis of the role of routine colonic evaluation after radiologically confirmed acute diverticulitis. Ann Surg 2014;259:263-272.

7. de Vries HS, Boerma D, Timmer R, van Ramshorst B, Dieleman LA, van Westreenen HL. Routine colonoscopy is not required in uncomplicated diverticulitis: a systematic review. Surg Endosc 2014;28:2039-2047.

8. Hinchey EJ, Schaal PG, Richard GK. Treatment of perforated diverticular disease of the colon. Adv Surg 1978;12:85-109.

9. Kaiser AM, Jiang JK, Lake JP, et al. The management of complicated diverticulitis an the role of computed tomography. Am J Gastroenterol 2005;100:910-917.

10. Sartelli M, Catena F, Ansaloni L, et al. WSES Guidelines for the management of acute left sided colonic diverticulitis in the emergency setting. World J Emerg Surg 2016;11:37.

11. Klarenbeek BR, de Korte N, van der Peet DL, Cuesta MA. Review of current classifications for diverticular disease and a translation into clinical practice. Int J Colorectal Dis 2012;27:207-214.

12. Andrade P, Ribeiro A, Ramalho R, Lopes S, Macedo G. Routine Colonoscopy after acute uncomplicated diverticulitis - challenging a putative indication. Dig Surg 2017;34:197-202.

13. Stollman N, Smalley W, Hirano I; AGA Institute Clinical Guidelines Committee. American Gastroenterological Association Institute Guideline on the Management of Acute Diverticulitis. Gastroenterology 2015;149:1944-1949.

14. Francis NK, Sylla P, Abou-Khalil M, et al. EAES and SAGES 2018 consensus conference on acute diverticulitis management: evidence-based recommendations for clinical practice. Surg Endosc 2019;33:2726-2741.

15. Kim MJ, Woo YS, Kim ER, et al. Is colonoscopy necessary after computed tomography diagnosis of acute diverticulitis? Intest Res 2014;12:221-228.

16. Ou G, Rosenfeld G, Brown J, et al. Colonoscopy after CTdiagnosed acute diverticulitis: Is it really necessary? Can J Surg 2015;58:226-231.

17. Soh NYT, Chia DKA, Teo NZ, Ong CJM, Wijaya R. Prevalence of colorectal cancer in acute uncomplicated diverticulitis and the role of the interval colonoscopy. Int J Colorectal Dis 2018;33:991-994.

18. Ramphal W, Schreinemakers JMJ, Seerden TCJ, Gobardhan PD. Tumour characteristics of patients with colorectal cancer after acute uncomplicated diverticulitis. Dig Dis 2018;36:362-368.

19. Grahnat CJ, Hérard S, Ackzell A, Andersson RE. High probability of an underlying colorectal cancer among patients treated for acute diverticulitis. A population-based cohort follow-up study. World J Surg 2016;40:2283-2288.

20. Daniels L, Ünlü Ç, de Wijkerslooth TR, et al. Yield of colonoscopy after recent CT-proven uncomplicated acute diverticulitis: a comparative cohort study. Surg Endosc 2015;29:2605-2613.

21. Horesh N, Saeed Y, Horesh H, et al. Colonoscopy after the first episode of acute diverticulitis: challenging management paradigms. Tech Coloproctol 2016;20:383-387.

22. Suhardja TS, Norhadi S, Seah EZ, Rodgers-Wilson S. Is early colonoscopy after CT-diagnosed diverticulitis still necessary? Int $J$ Colorectal Dis 2017;32:485-489. 